\title{
RELAÇÃO ENTRE O TAMANHO E A QUALIDADE FISIOLÓGICA DE SEMENTES DE FEIJÃO-CAUPI
}

\author{
Renan Thiago Carneiro Nunes ${ }^{1}$, Aderson Costa Araujo Neto ${ }^{1}$, Ubiratan Oliveira Souza ${ }^{2}$, \\ Josué Júnior Novaes Ladeia Fogaça ${ }^{1}$, Otoniel Magalhães Morais ${ }^{3}$
}

\footnotetext{
${ }^{1}$ Doutorando em Agronomia (Fitotecnia), Universidade Estadual do Sudoeste da Bahia - UESB, Vitória da Conquista, Bahia, Brasil.

${ }^{2}$ Docente do Instituto Federal de Educação, Ciência e Tecnologia Baiano, Campus Bom Jesus da Lapa, Bom Jesus da Lapa, Bahia, Brasil.

${ }^{3}$ Docente do Departamento de Fitotecnia e Zootecnia, Universidade Estadual do Sudoeste da Bahia, Vitória da Conquista, Bahia, Brasil.
}

RESUMO: A diferença no tamanho da semente no seu desempenho em campo e a sua relação com a qualidade fisiológica vêm sendo estudados por diversos autores, entretanto, a compreensão dos diferentes componentes do desempenho das sementes não é um assunto completamente esclarecido. Diante do exposto, o presente trabalho objetivou avaliar as diferenças na qualidade das sementes de feijão-caupi, cultivar BRS Guariba, provenientes de diferentes tamanhos e seus efeitos sobre a qualidade fisiológica. As sementes foram separadas por sua largura utilizando um jogo de peneiras de crivos circulares, sobrepostas. Foram obtidas cinco classes de largura, correspondendo às sementes retidas nas peneiras de números $14,15,16,17,18$ cujos diâmetros dos crivos foram de, respectivamente, 5,55; 5,95; 6,35; 6,$74 ; 7,14 \mathrm{~mm}$. Realizou-se a análise de variância e as médias foram comparadas pelo teste de Tukey a $5 \%$ de probabilidade. O tamanho das sementes não influencia no desempenho germinativo do feijão-caupi cv. BRS Guariba. Entretanto, as sementes maiores (Peneiras 17/6,74 mm e 18/7,14 mm) apresentam menor vigor em relação às menores.

Palavras-chave: Crivos. Germinação. Vigor. Vigna unguiculata.

\section{RELATIONSHIP BETWEEN THE SIZE AND PHYSIOLOGICAL QUALITY OF COWFEA SEEDS}

\begin{abstract}
The difference in seed size in your field performance and its relationship with the physiological quality have been studied by several authors, however, understanding the different components of the performance of the seeds is not a subject completely understood. Given the above, the objective of this study was to evaluate the differences in the quality of seeds, from seeds of different sizes and their effects on the physiological quality. The seeds were divided by its width using a set of sieves circular, overlapping screens. Five classes width were obtained, corresponding to the seeds retained on sieves numbers $14,15,16,17$, 18 whose diameters sieves were, respectively, 5.55; 5.95; 6.35; 6.74; $7.14 \mathrm{~mm}$. We performed analysis of variance and means were compared by Tukey test at $5 \%$ probability. The size of the seeds does not influence the germinative performance of cowpea cv. BRS Guariba.
\end{abstract}

Cultura Agronômica, Ilha Solteira, v.25, n.4, p.01-11, 2016 
However, the larger seeds (Sieves 17 / $6.74 \mathrm{~mm}$ and $18 / 7.14 \mathrm{~mm}$ ) show less vigor in relation to the smaller ones.

Key words: Riddles. Germination. Vigor. Vigna unguiculata.

\section{INTRODUÇÃO}

O feijão-caupi (Vigna unguiculata L. Walp.) também conhecido como feijão-fradinho e feijão-de-corda é uma leguminosa de clima tropical que apresenta grande importância socioeconômica, principalmente para as populações rurais das regiões Norte e Nordeste do Brasil. Atualmente a cultura tem se expandido para a região Centro-Oeste, onde a produção provém principalmente de médios e grandes produtores com cultivos mais tecnificados (FREIRE FILHO et al., 2011).

No Brasil são produzidos atualmente 1,6 milhões de hectares desta leguminosa, com produção de 822 mil toneladas de grãos. A maior produção concentra-se na região Nordeste, com $84 \%$ da área plantada e $68 \%$ da produção nacional (CONAB, 2013). Embora a espécie apresente ampla adaptação aos mais diversos ambientes, a cultura ainda apresenta uma produtividade média de grãos relativamente baixa, de aproximadamente $525 \mathrm{~kg} \mathrm{ha}^{-1}$. Entre as principais causas desta baixa produtividade está a utilização de baixo nível tecnológico, incluindo o uso de sementes de baixa qualidade, associado ao uso de cultivares tradicionais com baixo potencial produtivo (FREIRE FILHO et al., 2005).

A alta qualidade fisiológica de sementes é de grande importância, principalmente quanto à germinação uniforme, garantindo um melhor estande inicial de plantas. Sendo assim, sementes de alto vigor constituem-se em elemento básico e fundamental da cultura (MENDONÇA et al., 2003). Para Marcos Filho (2005) sementes de baixa qualidade, isto é, de potencial de germinação e vigor reduzidos, originam lavouras com baixa população de plantas, desuniformes, ocasionando sérios prejuízos econômicos.

A qualidade fisiológica da semente significa sua capacidade para desenvolver funções vitais, tais como, germinação, vigor e longevidade. Com isso, os efeitos sobre a qualidade geralmente, são traduzidos pelo decréscimo na porcentagem de germinação, aumento de plântulas anormais e por fim, redução do vigor das plântulas (TOLEDO et al., 2009). A uniformidade do tamanho é um dos atributos importantes no aspecto visual para a comercialização e, essencial para regulagem das semeadoras, pois permite controle do estande na semeadura e, em muitos casos, a economia de sementes por unidade de área (PAIVA et al., 2006).

Segundo Vazquez et al. (2012) classificar sementes por tamanho pode afetar o vigor inicial das plantas e os componentes agronômicos de produção. O tamanho da semente afeta o vigor da plântula resultante, sendo que, as sementes de maior tamanho dão origem a plântulas mais vigorosas (SANTOS et al., 2005).

Cultura Agronômica, Ilha Solteira, v.25, n.4, p.01-11, 2016 
O tamanho das sementes, em muitas espécies é indicativo de sua qualidade fisiológica, pois dentro do mesmo lote, a germinação e o vigor das sementes pequenas são menores que as de tamanhos médio e grande (ARAUJO NETO et al., 2014). Para Carvalho e Nakagawa (2012), as sementes de maior tamanho ou aquelas que apresentam maior densidade são aquelas que possuem normalmente, embriões bem formados e com maiores quantidades de reservas, sendo potencialmente as mais vigorosas. Segundo Pádua et al. (2010), sementes de maior tamanho apresentam correlações positivas com as taxas de crescimento inicial de plântulas, onde favorecem a um rápido crescimento de raiz e parte aérea, possibilitando melhor proveito das reservas nutricionais e hídricas do solo, assim como maior potencial de produtividade.

A classificação das sementes de feijão-caupi por tamanho após o processo de limpeza tem sido adotada por vários produtores. Apesar da escassez de pesquisas em relação à vantagem desta prática, ela tem sido utilizada como propaganda pelos produtores de sementes. Trés et al. (2010) observaram que as sementes de menores tamanho e peso originam plântulas menos vigorosas. Porém, outros pesquisadores trabalhando com parâmetros idênticos, não encontraram diferenças na qualidade das sementes de diferentes tamanhos (SILVA FILHO, 1994).

De acordo com Cherobini (2008) o uso de testes rápidos para avaliar o vigor das sementes é importante por fornecer ao produtor uma noção precisa quanto ao comportamento na semeadura. Sendo assim, o teste de condutividade elétrica baseia-se no princípio de que com o processo de deterioração, ocorre a lixiviação dos constituintes celulares das sementes embebidas em água, devido à perda da integridade dos sistemas celulares. Assim, os menores valores, correspondem a menor liberação de exsudatos, indicando alto potencial fisiológico, ou seja, sementes mais vigorosas, revelando menor intensidade de desorganização dos sistemas membranas das células (VIEIRA; KRZYZANOWSKI, 1999).

O teste de lixiviação de potássio tem sido utilizado como um indicador da integridade das membranas celulares, demonstrando ser um índice rápido de avaliação do vigor de sementes em algumas espécies, como feijão (BARROS et al., 1999) e milho (MIGUEL; MARCOS FILHO, 2002). Esse teste tem princípio semelhante ao de condutividade elétrica, baseando-se na integridade das membranas celulares das sementes, com a diferença em relação ao de condutividade elétrica, por determinar a quantidade total de íons liberados durante a embebição, enquanto que o de lixiviação de potássio quantifica-se somente o potássio lixiviado na solução, visto que, este é o principal íon inorgânico lixiviado pelas sementes durante a embebição (KIKUTI et al., 2008).

Embora a germinação e o vigor de sementes possam estar relacionados com o tamanho de semente, a influência deste parâmetro na qualidade fisiológica, não é um assunto completamente esclarecido. Assim, o presente trabalho objetivou avaliar as diferenças na qualidade das sementes de feijão-caupi, provenientes de diferentes tamanhos e seus efeitos sobre a qualidade fisiológica.

Cultura Agronômica, Ilha Solteira, v.25, n.4, p.01-11, 2016 


\section{MATERIAL E MÉTODOS}

Este estudo foi conduzido no Laboratório de Tecnologia de Sementes da Universidade Estadual do Sudoeste da Bahia, campus de Vitória da Conquista, BA, com sementes de feijãocaupi, cultivar BRS Guariba, colhidas na safra 2013/2014, produzidas no campus da Universidade Estadual do Sudoeste da Bahia de Vitória da Conquista-BA, localizado a 14²53' de Latitude sul e $40^{\circ} 48^{\prime}$ de Longitude oeste, com altitude média de 876,91 m.

As sementes foram passadas por um jogo de peneiras de crivos circulares, sobrepostas, o que possibilitou a separação pela largura. Foram obtidas cinco classes de largura, correspondendo às sementes retidas nas peneiras de números $18,17,16,15,14$ cujos diâmetros dos crivos foram de, respectivamente, 7,14; 6,74; 6,35; 5,95 e $5,55 \mathrm{~mm}$. A determinação do teor de água e peso de mil sementes foi realizada para todas as classes de tamanho. Na determinação do teor de água foram utilizadas quatro subamostras de 50 sementes. Para a determinação do peso de mil sementes foram separadas oito amostras de cem sementes, seguindo a metodologia descrita nas Regras para Análises de Sementes (BRASIL, 2009).

Para avaliar o efeito do tamanho das sementes foram analisadas as seguintes variáveis:

Número de sementes por quilograma - calculou-se o número de sementes por $\mathrm{kg}$ com oito repetições de 100 sementes de cada lote, segundo Oliveira (2007) a partir da seguinte equação: $\mathbf{N}=(\mathbf{1 0 0 0} \times \mathbf{1 0 0 0}) / \mathbf{P M S}$, Onde: $\mathrm{N}=$ número de sementes por $\mathrm{kg}$; $\mathrm{PMS}=$ peso de mil sementes em gramas.

Teste de germinação - quatro repetições de 50 sementes foram semeadas em rolos de papel germitest umedecidos com água destilada na quantidade equivalente a 2,5 vezes a massa do substrato seco e mantidos em germinador do tipo Biochemical Oxigen Demand (B.O.D.), regulado a temperatura de $25^{\circ} \mathrm{C}$. As avaliações foram realizadas aos cinco e oito dias após a semeadura, e os resultados expressos em porcentagem média com base no número de plântulas normais, considerando-se como normais as plântulas com as estruturas essenciais perfeitas (BRASIL, 2009).

Primeira contagem de germinação - realizada simultaneamente com o teste de germinação, sendo a porcentagem acumulada de plântulas normais no quinto dia após a semeadura.

Condutividade elétrica - determinada de acordo com a metodologia descrita por Vieira e Krzyzanowski (1999). Foram utilizadas duas repetições de 50 sementes para cada peneira. As sementes foram pesadas em balança analítica com precisão de um miligrama e colocadas em copos plásticos (sistema de copo ou condutividade de massa ou "bulk conductivity") contendo $25 \mathrm{~mL}$ de água deionizada, permanecendo em estufa incubadora regulada a temperatura de $25^{\circ} \mathrm{C}$, por 24 horas. A avaliação foi realizada após o conteúdo ter sido agitado suavemente com bastão de vidro, sendo a condutividade elétrica medida com condutivímetro

Cultura Agronômica, Ilha Solteira, v.25, n.4, p.01-11, 2016 
digital de bancada, da marca Digimed DM-31. Os valores médios da condutividade elétrica de cada lote foram expressos em $\mu \mathrm{S} \mathrm{cm}^{-1} \mathrm{~g}^{-1}$ de sementes.

Lixiviação de potássio $\left(\mathbf{K}^{+}\right)$- quatro subamostras de 50 sementes de cada tratamento foram pesadas em balança com precisão de $0,0001 \mathrm{~g}$, colocadas em copos plásticos contendo $75 \mathrm{~mL}$ de água deionizada e mantidas em germinador regulado a temperatura de $20^{\circ} \mathrm{C}$ por 24 horas. Transcorrido este período, a solução que continha as sementes foi acondicionada em frascos plásticos, identificados e encaminhados para a determinação do íon potássio $\left(\mathrm{K}^{+}\right)$. A determinação de $\mathrm{K}^{+}$foi realizada empregando-se o método de fotometria de chama e os resultados expressos em ppm K.g ${ }^{-1}$ de semente (MIGUEL; MARCOS FILHO, 2002).

A análise estatística dos dados foi realizada utilizando-se o delineamento experimental inteiramente ao acaso, em quatro repetições para cada tratamento. Os dados obtidos foram submetidos à análise de variância e as médias comparadas pelo teste Tukey a 5\% de probabilidade por meio do programa estatístico SAEG (Sistema para Análises Estatísticas e Genéticas), versão 9.1.

\section{RESULTADOS E DISCUSSÃO}

Os resultados da análise de variância (Tabela 1) indicaram que houve diferença significativa $(\mathrm{p}<0,05)$ entre os tratamentos para as variáveis de peso de mil sementes, germinação, número de sementes por quilograma, condutividade elétrica e lixiviação de potássio.

Tabela 1. Análise de variância das diferentes classes de peneiras para os testes: teor de água (TA), peso de mil sementes (PMS), germinação $(\mathrm{G})$, primeira contagem de germinação (PCG), número de sementes por quilograma (NSQ), condutividade elétrica (CE) e lixiviação de potássio (LP). Vitória da Conquista-BA, 2015.

\begin{tabular}{|c|c|c|c|c|c|c|c|c|}
\hline & & TA & PMS & G & PCG & NSQ & $\mathrm{CE}$ & LP \\
\hline FV & GL & $--\cdot$ & ---- 9 & $6----$ & ---- & $(\mathrm{kg})$ & $\left(\mu \mathrm{S} \mathrm{cm}^{-1} \mathrm{~g}^{-1}\right)$ & $\left(\mathrm{ppm} \mathrm{K} \mathrm{K}^{+} \cdot \mathrm{g}^{-1}\right)$ \\
\hline TRAT & 4 & $0,084^{\text {ns }}$ & $7375,5^{*}$ & $69,7^{*}$ & $5,3^{\mathrm{ns}}$ & $6756394,0^{*}$ & $8874,18^{*}$ & $984668,6^{*}$ \\
\hline RES & 15 & 0,0485 & 0,474 & 22,2 & 1,93 & 238,5 & 201,10 & 7780,2 \\
\hline $\mathrm{CV}(\%)$ & & 1,840 & 0,362 & 5,537 & 1,414 & 0,281 & 0,362 & 2,790 \\
\hline
\end{tabular}

FV: fatores de variação; GL: graus de liberdade; *Significativo pelo teste "F" a 5\% de probabilidade. ns - não significativo.

A Tabela 2 apresenta os valores médios para teor de água, peso de mil sementes e número de sementes por quilograma de feijão caupi cv. BRS Guariba de diferentes tamanhos. Para o teor de água nas sementes não foi verificada diferença entre os tratamentos (Tabela 2). O teor de água das sementes encontrava-se uniforme, com variação de $0,31 \%$, inferior à amplitude máxima recomendada que é de 1 a 2 pontos percentuais (MARCOS FILHO, 1999). Segundo esse mesmo autor, esse aspecto é de suma importância na execução dos testes, uma vez que a uniformização do teor de água das sementes é imprescindível para padronização das avaliações e obtenção de resultados consistentes. No entanto, Coimbra (2007) relata que

Cultura Agronômica, Ilha Solteira, v.25, n.4, p.01-11, 2016 
o teor de água inicial das sementes é um dos fatores primordiais para a regularização dos testes de vigor a serem realizados, enfatizando que o teor elevado de água pode favorecer o desempenho das sementes nos testes. Para Andrade et al. (1999), o teor de umidade inicial está diretamente relacionado com a baixa germinação de sementes de feijão, uma vez que sementes colhidas com elevados teores de umidade são mais susceptíveis a danos mecânicos, que aquelas colhidas com um teor de umidade menor.

Tabela 2. Teor de água, peso de mil de sementes e número de sementes por quilograma, em sementes de feijão-caupi, cultivar BRS Guariba, classificadas pela largura. UESB, Vitória da Conquista-BA, 2015.

\begin{tabular}{lccc}
\hline Classe de largura & $\begin{array}{c}\text { Teor de água } \\
(\%)\end{array}$ & $\begin{array}{c}\text { Peso de mil sementes } \\
(\mathrm{g})\end{array}$ & $\begin{array}{c}\mathrm{N}^{\circ} \text { de sementes / } \\
\mathrm{kg}\end{array}$ \\
\hline Peneira 14 $(5,55 \mathrm{~mm})$ & $11,95 \mathrm{a}$ & $135,79 \mathrm{e}$ & $7386,08 \mathrm{a}$ \\
Peneira $15(5,95 \mathrm{~mm})$ & $11,85 \mathrm{a}$ & $164,30 \mathrm{~d}$ & $6068,34 \mathrm{~b}$ \\
Peneira $16(6,35 \mathrm{~mm})$ & $12,10 \mathrm{a}$ & $189,42 \mathrm{c}$ & $5279,14 \mathrm{c}$ \\
Peneira $17(6,74 \mathrm{~mm})$ & $11,80 \mathrm{a}$ & $217,68 \mathrm{~b}$ & $4596,07 \mathrm{~d}$ \\
Peneira $18(7,14 \mathrm{~mm})$ & $12,12 \mathrm{a}$ & $244,47 \mathrm{a}$ & $4090,53 \mathrm{e}$ \\
\hline CV $(\%)$ & 1,84 & 0,362 & 0,281 \\
\hline
\end{tabular}

Médias seguidas pelas mesmas letras na coluna não diferem entre si pelo teste Tukey a 5\% de probabilidade.

Ainda na Tabela 2, observa-se que o peso de mil sementes diferiu em todas as classes de tamanho, onde as sementes com maior massa foram verificadas entre as sementes das classes de maior tamanho (sementes classificadas nas peneiras de 17 e 18). Jauer et al. (2002) observaram diferenças significativas no peso de mil sementes de feijão (Phaseolus vulgaris L.) das cultivares TPS Nobre, Xamego e IAPAR 44, com os maiores pesos verificados nas sementes grandes (> $6 \mathrm{~mm}$ ), seguido da mistura e das sementes pequenas $(<6 \mathrm{~mm})$. Abud et al. (2010) também observaram que com o aumento do tamanho das sementes de cártamo (Carthamus tinctorius L.) houve aumento proporcional no peso de mil sementes. Esta característica é de grande importância por ser bastante utilizada para cálculo de densidade de semeadura, e para pressupor a qualidade das sementes, quantidade de reservas, estado de maturação e sanidade (BRASIL, 2009).

Em relação ao número de sementes por quilograma, observou-se que a classificação na peneira 14 apresentou maior número de sementes por quilograma $(7386,08 \mathrm{~kg}$ ) (Tabela 2), diferindo estatisticamente das demais classes de peneiras analisadas, onde à medida que aumentou o tamanho da peneira, menor foi o número de sementes por quilograma. A peneira (18) foi a que apresentou um menor número de sementes por quilograma (4090,53 kg). Esta relação tem importância prática do ponto de vista econômico, pois o produtor busca a obtenção de sementes bem formadas, consequentemente mais pesadas, aumentando seu lucro/produção e sua qualidade fisiológica.

$\mathrm{Na}$ avaliação da primeira contagem de germinação, constatou-se diferença entre as classes de largura das peneiras estudadas, sendo registrada maior germinação nas sementes de tamanho de peneira $16(91 \%)$, em relação às sementes de peneira 18 (81\%) (Tabela 3). Cultura Agronômica, Ilha Solteira, v.25, n.4, p.01-11, 2016 
Esses resultados, possivelmente, podem estar relacionados ao contraste na quantidade de sementes presentes em cada classe de tamanho, visto que as sementes retidas na peneira 16 (3,97 $\mathrm{mm}$ de largura) foram as de maior proporção, sendo a classe de maior representatividade, com aproximadamente $37 \%$ do total; o que sugere que o tamanho da semente seja uma característica marcada geneticamente para esta cultivar, conferindo menor vigor para as sementes maiores.

Resultados distintos foram encontrados por Pádua et al. (2010), que ao estudar a influência do tamanho da semente de três cultivares de soja (Glycine max) na qualidade fisiológica, constataram que as sementes maiores (peneira 7,0 $\mathrm{mm}$ ) apresentam maiores porcentagens de germinação e de vigor em relação às menores (peneira 6,0 mm). Por outro lado, Araujo Neto et al. (2014), ao estudar o comportamento germinativo de sementes de feijão-caupi, cultivar Novaera, não encontraram diferenças entre as classes de largura, indicando que o tamanho das sementes não tem influência no percentual de germinação na ocasião da primeira contagem.

Tabela 3. Retenção, germinação e primeira contagem de germinação, em sementes de feijãocaupi, cultivar BRS Guariba, classificadas pela largura. UESB, Vitória da Conquista - BA, 2015 .

\begin{tabular}{|c|c|c|c|}
\hline Clacse de laroura & Retenção & Primeira contagem & Germinação \\
\hline Peneira $14(5,55 \mathrm{~mm})$ & 10,2 & $84 \mathrm{ab}$ & $98 \mathrm{a}$ \\
\hline Peneira $15(5,95 \mathrm{~mm})$ & 27,3 & $83 \mathrm{ab}$ & $99 \mathrm{a}$ \\
\hline Peneira $16(6,35 \mathrm{~mm})$ & 36,6 & $91 \mathrm{a}$ & $100 \mathrm{a}$ \\
\hline Peneira $17(6,74 \mathrm{~mm})$ & 21,4 & $88 \mathrm{ab}$ & $98 \mathrm{a}$ \\
\hline Peneira $18(7,14 \mathrm{~mm})$ & 4,5 & $81 \mathrm{~b}$ & $97 \mathrm{a}$ \\
\hline $\mathrm{CV}(\%)$ & & 5,37 & 1,41 \\
\hline
\end{tabular}

Médias seguidas pelas mesmas letras na coluna não diferem pelo teste de Tukey a 5\% de probabilidade.

Quanto ao percentual de germinação (Tabela 3), verificou-se que não houve diferença significativa entre as classes de largura, onde mais de $97 \%$ das sementes germinaram ao final do teste, aos oito dias após o semeio, sugerindo que a mobilização de substâncias de reservas e translocação para estruturas de crescimento apresentaram-se de forma semelhante (CARVALHO; NAKAGAWA, 2012).

Concordando com os resultados obtidos, Jauer et al. (2002) constataram que o tamanho das sementes não influenciou na germinação das cultivares de feijoeiro (Phaseolus vulgaris L.) TPS Bionobre, TPS Nobre e Xamego. Abud et al. (2010) também constataram que os dados de porcentagem de germinação de sementes de cártamo (Carthamus tinctorius L.) de diferentes tamanhos não foram estatisticamente significativos.

Na Tabela 4, verifica-se que os valores referentes à condutividade elétrica e a lixiviação de potássio variaram em função das classes de tamanho. As sementes retidas nas peneiras 17 $(6,74 \mathrm{~mm})$ e $18(7,14 \mathrm{~mm})$ apresentaram maior lixiviação de eletrólitos, com maiores 
resultados de condutividade elétrica $\left(230,22\right.$ e $284,77 \mu \mathrm{S} \mathrm{cm}^{-1} \mathrm{~g}^{-1}$, respectivamente), indicando que as sementes maiores apresentam menor vigor em relação às menores (peneiras 14, $15 \mathrm{e}$ 16), as quais obtiveram os menores valores para esta variável. Esses resultados discordam dos obtidos por Cazetta et al. (1995), ao estudarem o efeito do tamanho no desempenho germinativo de sementes de feijoeiro (P. vulgaris). Marcos Filho (2005) aponta que o teste de condutividade elétrica tem se mostrado eficiente para a avaliação do vigor de sementes de várias espécies. Dias et al. (1998) concluíram que o teste de condutividade elétrica foi eficiente para a avaliação do potencial fisiológico das sementes de feijão-de-vagem e quiabo, fato também observado nesta pesquisa.

Tabela 4. Condutividade elétrica $\left(\mu \mathrm{S} \mathrm{cm}^{-1} \mathrm{~g}^{-1}\right)$ e lixiviação de potássio ( $\mathrm{ppm} \mathrm{K}^{+} \cdot \mathrm{g}^{-1}$ ) em sementes de feijão-caupi, cultivar BRS Guariba, classificadas pela largura. UESB, Vitória da Conquista - BA, 2015.

\begin{tabular}{ccc}
\hline Classe de largura & $\begin{array}{c}\text { Condutividade elétrica } \\
\left(\mu \mathrm{S} \mathrm{cm}^{-1} \mathrm{~g}^{-1}\right)\end{array}$ & $\begin{array}{c}\text { Lixiviação de potássio } \\
\left(\mathrm{ppm} \mathrm{K}^{+} \cdot \mathrm{g}^{-1}\right)\end{array}$ \\
\hline Peneira 14 $(5,55 \mathrm{~mm})$ & $171,82 \mathrm{c}$ & $2542,50 \mathrm{e}$ \\
Peneira 15 $(5,95 \mathrm{~mm})$ & $182,57 \mathrm{c}$ & $2869,32 \mathrm{~d}$ \\
Peneira 16 $(6,35 \mathrm{~mm})$ & $184,17 \mathrm{c}$ & $3122,14 \mathrm{c}$ \\
Peneira 17 $(6,74 \mathrm{~mm})$ & $230,22 \mathrm{~b}$ & $3457,02 \mathrm{~b}$ \\
Peneira 18 $(7,14 \mathrm{~mm})$ & $284,77 \mathrm{a}$ & $3815,14 \mathrm{a}$ \\
\hline CV $(\%)$ & 6,73 & 2,79 \\
\hline
\end{tabular}

Médias seguidas pelas mesmas letras na coluna não diferem pelo teste de Tukey a 5\% de probabilidade.

Para a lixiviação de potássio (Tabela 3), os menores resultados foram registrados na embebição das sementes retidas nas peneiras $14(5,55 \mathrm{~mm}), 15(5,95 \mathrm{~mm})$ e $16(6,35 \mathrm{~mm})$ $\left(2542,5 ; 2869,32\right.$ e $3122,14 \mathrm{ppm} \mathrm{K}^{+} . \mathrm{g}^{-1}$, respectivamente), evidenciando maior vigor dessas sementes em relação as maiores retidas nas peneiras $17(6,74 \mathrm{~mm})$ e $18(7,14 \mathrm{~mm})$. Resultados similares foram encontrados por Becker et al. (2000), ao verificarem que com a redução do peso de mil sementes (tamanho), a entrada de água nas sementes de soja foi facilitada por seu menor tamanho, acarretando assim em uma menor lixiviação de potássio.

De acordo com Marcos Filho (2005), uma menor lixiviação de potássio evidencia uma melhor qualidade fisiológica das sementes, por ocorrer menor liberação de exsudatos, indicando alto potencial fisiológico (maior vigor). Quanto menor a liberação de íons de potássio, maior a integridade das membranas celulares, e consequentemente, maior vigor as sementes terão, sugerindo uma estreita ligação entre lixiviação de minerais e danos à membrana (KRZYZANOWSKI et al., 1999).

Em trabalho realizado por Woodstock et al. (1985) com sementes de algodão, observaram a deterioração das membranas através da microscopia eletrônica, ressaltando que a lixiviação de íons individuais, como o $\mathrm{K}^{+} \mathrm{e} \mathrm{Ca}^{2+}$, foram melhores indicadores da qualidade das sementes que índices gerais, como a condutividade. Da mesma forma que ocorre no teste de condutividade elétrica, sementes menos vigorosas apresentam menor velocidade de 
estruturação das membranas quando embebidas em água, tendo como consequência maior liberação de exsudatos para o exterior da célula que aquelas mais vigorosas (HAMPTON; TEKRONY, 1995; MARCOS FILHO, 2005), consequentemente apresentando maior liberação de potássio.

\section{CONCLUSÃO}

O tamanho das sementes não influencia no desempenho germinativo do feijão-caupi cv. BRS Guariba.

As sementes maiores (Peneiras 17/6,74 mm e 18/7,14 mm) de feijão-caupi cv. BRS Guariba apresentam menor vigor em relação às menores.

\section{AGRADECIMENTOS}

À Fundação de Amparo à Pesquisa do Estado da Bahia - FAPESB, pela bolsa de estudo concedida ao primeiro autor.

\section{REFERÊNCIAS BIBLIOGRÁFICAS}

ANDRADE, E. T.; CORRÊA, P. C.; MARTINS, J. H.; ALVARENGA, E. M. Avaliação de dano mecânico em sementes de feijão por meio de condutividade elétrica. Revista Brasileira de Engenharia Agrícola e Ambiental, Campina Grande, v. 3, n. 1, p.54-60, 1999.

ARAUJO NETO, A. C.; NUNES, R. T. C.; ROCHA, P. A. ÁVILA, J. S.; MORAIS, O. M. Germinação e vigor de sementes de feijão-caupi (Vigna unguiculata (L.) Walp.) de diferentes tamanhos. Revista Verde de Agroecologia e Desenvolvimento Sustentável, Pombal, v. 9, n. 2, p.71-75, 2014.

ABUD, H. F.; REIS, R. G. E.; INNECCO, R. I.; BEZERRA, A. M. E. Emergência e desenvolvimento de plântulas de cártamos em função do tamanho das sementes. Revista Ciência Agronômica, Fortaleza, v. 41, n. 1, p.95-99, 2010.

BARROS, M. A.; OHSE, S.; MARCOS FILHO, J. Ion leakage as an indicator of vigor in field bean seeds. Seed Technology, Lansing, v. 21, n. 1, p.44-48, 1999.

BECKER, O. P.; MIGUEL, M. H.; MARCOS FILHO, J. Absorção de água e potencial fisiológico em sementes de soja de diferentes tamanhos. Scientia Agricola, Piracicaba, v. 57, n. 4, p.671-675, 2000.

BRASIL. Ministério da Agricultura, Pecuária e Abastecimento - Secretária de Defesa Agropecuária. Regras para Análise de Sementes. Brasília: MAPA/ACS, 2009. 395 p.

CARVALHO, N. M.; NAKAGAWA, J. Sementes: ciência, tecnologia e produção. 5. ed. Jaboticabal: FUNEP, 2012. 590 p.

Cultura Agronômica, Ilha Solteira, v.25, n.4, p.01-11, 2016 
CAZETTA, J. O.; SADER, R.; IKEDA, M. Efeito do tamanho no desempenho germinativo de sementes de feijoeiro (Phaseolus vulgaris L.). Científica, Jaboticabal, v. 23, n. 1, p.6571,1995 .

CHEROBINI, E. A. I.; MUNIZ, M. F. B.; BLUME, E. Avaliação da qualidade de sementes e mudas de cedro. Ciência Florestal, Santa Maria, v. 18, n. 1, p.65-73, 2008.

COIMBRA, R. A. Teste de germinação com acondicionamento dos rolos de papel em sacos plásticos. Revista Brasileira de Sementes, Londrina, v. 29, n. 1, p.92-97, 2007.

CONAB - Companhia Nacional de Abastecimento. Acompanhamento da safra brasileira de grãos. v. 1 - Safra 2013/14, n. 3 - Terceiro Levantamento, Brasília, p.1-72, 2013. Disponível em: http://www.conab.gov.br/OlalaCMS/uploads/arquivos/14_01_10_10_12_36_boletim_portu gues_dezembro_2013.pdf. Acesso em: $12 \mathrm{dez} .2015$.

DIAS, D. C. F. S.; VIEIRA, A. N.; BHÉRING, M. C. Condutividade elétrica e lixiviação de potássio para avaliação do vigor de sementes de hortaliças: feijão vagem e quiabo. Revista Brasileira de Sementes, Londrina, v. 20, n. 2, p.408-413, 1998.

FREIRE FILHO, F. R.; LIMA, J. A. A.; RIBEIRO, V. Q. (Ed.). Feijão-caupi: avanços tecnológicos. Brasília: Embrapa Informações Tecnológicas, 2005. 519 p.

FREIRE FILHO, F. R.; RIBEIRO, V. Q.; ROCHA, M. M.; SILVA, K. J. D.; NOGUEIRA, M. S. R.; RODRIGUES, E. V. Feijão-caupi no Brasil: produção, melhoramento genético, avanços e desafios. Teresina: Embrapa Meio-Norte, 2011. 84 p.

HAMPTON, J. G.; TeKRONY, D. M. (Eds.). Handbook of vigour test methods. 3. ed. Zurich: International Seed Testing Association, 1995. 117 p.

JAUER, A.; MENEZES, N. L.; GARCIA, D. C. Tamanho de sementes na qualidade fisiológica de cultivares de feijoeiro comum. Revista da Faculdade de Zootecnia, Veterinária e Agronomia, Uruguaiana, v. 9, n. 1, p.121-127, 2002.

KIKUTI, H.; MEDINA, P. F.; KIKUTE, A. L. P.; RAMOS, N. P. Teste de lixiviação de potássio para avaliação do vigor de sementes de amendoim. Revista Brasileira de Sementes, Londrina, v. 30, n. 1, p.10-18, 2008.

KRZYZANOWSKI, F. C.; VIEIRA, R. D.; FRANCA NETTO, J. B. (Ed.). Vigor de sementes: conceitos e testes. Londrina: ABRATES, 1999. 218 p.

MARCOS FILHO, J. Teste de envelhecimento acelerado. In: KRZYZANOWSKI, F. C.; VIEIRA, R. D.; FRANÇA NETO, J. B. (Ed.) Vigor de sementes: conceitos e testes. Londrina: ABRATES, 1999. cap. 3, p.1-24.

MARCOS FILHO, J. Fisiologia de sementes de plantas cultivadas. Piracicaba: Fealq, 2005. $495 \mathrm{p}$.

Cultura Agronômica, Ilha Solteira, v.25, n.4, p.01-11, 2016 
MENDONÇA, E. A. F.; RAMOS, N. P.; FESSEL, S. A. Adequação da metodologia do teste de deterioração controlada para sementes de brócolis (Brassica oleracea L. - var. Itálica). Revista Brasileira de Sementes, Londrina, v. 25, n. 1, p.18-24, 2003.

MIGUEL, M. V. C.; MARCOS FILHO, J. Potassium leakage and maize seed physiological potential. Scientia Agricola, Piracicaba, v. 59, n. 2, p.315-319, 2002.

OLIVEIRA, O. S. Tecnologia de sementes florestais. Curitiba: Imprensa Universitária, 2007. $185 \mathrm{p}$.

PÁDUA, G. P.; ZITO, R. K.; ARANTES, N. E.; FRANÇA NETO, J. B. Influência do tamanho da semente na qualidade fisiológica e na produtividade da cultura da soja. Revista Brasileira de Sementes, Londrina, v. 32, n. 3 p.09-16, 2010.

PAIVA, B. M.; ALVES, R. M.; HELENO, N. M. Aspecto socioeconômico da soja. Informe Agropecuário, Belo Horizonte, v. 27, n. 230, p.7-14, 2006.

SANTOS, P. M.; REIS, M. S.; SEDIYAMA, T.; ARAUJO, E. F.; CECON, P. R.; SANTOS, M. R. Efeito da classificação por tamanho da semente de soja na sua qualidade fisiológica durante $\mathrm{o}$ armazenamento qualidade fisiológica durante o armazenamento. Acta Scientiarum. Agronomy, Maringá, v. 27, n. 3, p.395-402, 2005.

SILVA FILHO, P. M. Desempenho de plantas e sementes de soja classificadas por tamanho e densidade. 1994. 64 f. Dissertação (Mestrado em Ciencia e Tecnologia de Sementes) - Universidade Federal de Pelotas, Pelotas, 1994.

TOLEDO, M. Z.; FONSECA, N. R.; CÉSAR, M. L.; SORATTO, R. P.; CAVARIANI, C.; CRUSCIOL, C. A. C. Qualidade fisiológica e armazenamento de sementes de feijão em função da aplicação tardia de nitrogênio em cobertura. Revista Pesquisa Agropecuária Tropical, Goiânia, v. 39, n. 2, p.124-133, 2009.

TRÉS, S. P.; ORSO, G.; BRAND, A. J.; SANTOS, E. L. Avaliação do vigor em sementes de soja (Glycine $\max$ (L.) Merrill) em função do tamanho. Cultivando o Saber, Cascavel, v. 3, n. 2, p.31-37, 2010.

VAZQUEZ, G. H.; ARF, O.; SARGI, B. A.; PASSOA, A. C. O. Influência do tamanho e da forma da semente de milho sobre o desenvolvimento da planta e a produtividade de grãos. Bioscience Journal, Uberlândia, v. 28, n. 1, p.16-24, 2012.

VIEIRA, R. D.; KRZYZANOWSKI, F. C. Teste de condutividade elétrica. In: KRZYZANOWSKI, F.C.; VIEIRA, R. D.; FRANCA-NETTO, J. B. Vigor de sementes: conceitos e testes. Londrina: ABRATES, 1999. cap. 4, p. 1-26.

WOODSTOCK, L. W.; FURMAN, K.; LEFFLER, H. R. Relationship between weathering deterioration and germination, respiratory metabolism, and mineral leaching from cottonseeds. Crop Science, Madison, v. 25, n. 3, p.459-466, 1985.

Cultura Agronômica, Ilha Solteira, v.25, n.4, p.01-11, 2016 